\title{
GCU
}

Glasgow Caledonian

University

University for the Common Good

\section{Valuing lives equally in a benefit-cost analysis of safety projects: a method to reconcile theory and practice}

Baker, Rachel M.; Chilton, S. M.; Jones-Lee, M. W.; Metcalf, H. R.T.

Published in:

Safety Science

DOI:

10.1016/j.ssci.2008.10.009

Publication date:

2009

Document Version

Author accepted manuscript

Link to publication in ResearchOnline

Citation for published version (Harvard):

Baker, RM, Chilton, SM, Jones-Lee, MW \& Metcalf, HRT 2009, 'Valuing lives equally in a benefit-cost analysis of safety projects: a method to reconcile theory and practice', Safety Science, vol. 47, no. 6, pp. 813-816.

https://doi.org/10.1016/j.ssci.2008.10.009

\section{General rights}

Copyright and moral rights for the publications made accessible in the public portal are retained by the authors and/or other copyright owners and it is a condition of accessing publications that users recognise and abide by the legal requirements associated with these rights.

Take down policy

If you believe that this document breaches copyright please view our takedown policy at https://edshare.gcu.ac.uk/id/eprint/5179 for details

of how to contact us. 


\title{
Valuing lives equally in a benefit-cost analysis of safety projects: a method to reconcile theory and practice.
}

\author{
Baker, R., Chilton, S.M*., Jones-Lee, M.W and Metcalf, H.R.T \\ Newcastle University Business School - Economics, Newcastle upon Tyne, UK \\ *s.m.chilton@newcastle.ac.uk \\ Newcastle University Business School-Economics \\ Ridley Building, \\ Claremont Road, \\ Newcastle NE1 7RU, \\ United Kingdom
}

$+44-191-222-6549$

\begin{abstract}
A Value of Statistical Life (VSL) is used in cost-benefit analysis (CBA) as a monetary measure of the benefits to people from small risk reductions that arise from safety projects. Despite its widespread use in a number of countries, the concept of a VSL remains controversial, not least because it implies acceptance of the underlying ethical assumptions of CBA together with the idea that 'social welfare' can be measured and aggregated in some manner. In addition, to comply with theory, variable VSLs for different groups within society would be advocated. However, without fail, empirically, it is the case that those countries that employ a willingness to pay based approach to benefit-cost analysis of a safety project appraisal tend to use a single value for that accident context that is independent of the per capita income level, or indeed other personal characteristics, of the sub-group in society to which the safety improvement will actually apply. This article presents a straightforward, but theoretically justified adaptation to the calculation of a VSL which allows empirical practice by policymakers i.e. the application of a "common" VSL for any particular hazard within a given society, to be compatible with a CBA decision making approach.
\end{abstract}

Keywords: Value of Statistical Life. Valuing Lives Equally. 


\section{Introduction}

It is becoming increasingly common practice in developed countries for government agencies to employ willingness to pay (WTP) - based values of safety in transport project appraisal and, indeed, in the case of several other hazards such as air pollution, fire safety, or flood risks. For example, in the UK the Department for Transport and other public sector agencies use a WTP-based Value of a Statistical Life (VSL) of roughly £1.5 million for all causes of death except cancer, where a value twice this size is applied ${ }^{1}$.

It is important to stress that a VSL is not a price on life or the value of preventing the death of one person. Instead a VSL is used in cost-benefit analysis (CBA) as a monetary measure of the benefits to people from small risk reductions that arise from safety projects. The VSL is derived by assuming a large group of $\mathrm{n}$ individuals who are presented with the opportunity in the forthcoming time period to reduce the risk of death by $1 / \mathrm{n}$ per person through the introduction of a safety improvement project. Jones-Lee (1989) and Viscusi (1998) show that, in this case, the mathematical expectation of lives saved is ' 1 '.

The purpose of CBA within safety policy is to facilitate resource allocation by attempting to make explicit any changes in social welfare arising from implementation of such policies. The ethical principles underlying the measurement of this change in social welfare within CBA are no more restrictive than the assumption that peoples' preferences should be accounted for through utility indices that must increase if a policy is to be welfare improving. The principle of Pareto efficiency guides CBA. It states that an allocation of resources is Pareto efficient if no alternative allocation could make any individual better off without making at least one individual worse off. Ideally, safety policymakers, given appropriate information on social welfare, would be able to rank safety polices (with their associated Pareto efficient allocations) to identify the best policy i.e. the one delivering the highest social welfare.

\footnotetext{
${ }^{1}$ This is to take some account of the fact that a cancer death is preceded by a period - sometimes protracted - of pain and suffering, whereas in other domains the death is assumed to be more or less instantaneous, albeit premature.
} 
Unfortunately, Arrow's (1973) Impossibility Theorem demonstrates that it is extremely difficult to derive a complete and consistent choice rule exclusively from individual preferences. Nevertheless, it is still possible to judge the benefits of a safety policy (captured by the VSL), and hence the allocation it produces, relative to a situation where no safety policy was introduced i.e. the baseline, or status-quo. Thus, while it may be very difficult to see the top of the mountain that we are trying to climb, it is nonetheless fairly easy to know whether or not we are moving in an upwards direction.

It is also almost certainly the case that many safety polices do not create direct Pareto improvements. Instead, there are winners and losers. For example, speedbumps on roads reduce the risk of fatalities but add to journey time. How to aggregate such gains and losses? The ethical principle underlying the aggregation process within CBA is that a policy is said to create a Potential Pareto Improvement (PPI) if the winners i.e. general road users, could in principle make a compensating transfer to the losers i.e. car drivers such that the former are at least as well off as they were without the speed bump (ex post, they have reduced their risk of death due to the speed bump but would have sacrificed income to car drivers to compensate them). Meanwhile, the losers ex post are no worse off, since the inconvenience of the slower journey time would be compensated for by the increased income. Whether any transfers actually take place is an empirical question for policymakers. In theory, for CBA to comply with these ethical underpinnings, it is merely sufficient that the possibility exists for a PPI.

In order to identify whether a safety policies generates a PPI, it is necessary to translate any physical impacts into a common unit of measurement to aggregate gains and losses across individuals. By observing, or asking, a person's willingness to trade risk reductions for money (effectively a metric for all other goods) we can place a money value on the benefits of these risk reductions to the individual. If the gain to the individual is positive, willingness to pay (WTP) is elicited. If the gain is negative i.e. a loss, then willingness to accept (WTA) is a more appropriate measure. However, given 
that safety is typically viewed as a normal $\operatorname{good}^{2}$ - at least for small risk reductions WTP values for a risk reduction is elicited from a sample of the affected population and aggregated to generate a $\mathrm{VSL}^{3}$.

Assuming a policy can generate a PPI, then aggregating these benefits would generate a so-called 'social surplus'. The issue is whether this is a reasonable proxy for social welfare? If not, it would be of little use in a CBA. Economists express social welfare in terms of a social welfare function which, although merely an analytical construct, provides a powerful framework within which to assess the impact on peoples' wellbeing of various exogenous changes, in our case a safety policy. Much attention has been paid to developing notions of social welfare that might be considered reasonable and consistent with the PPI criteria. A discussion of this is clearly beyond the scope of this paper, but suffice to say that most CBA are underpinned by a very general form of social welfare function,

$$
\mathrm{W}=\mathrm{W}\left(u_{1}, u_{2}, \ldots u_{m}\right)
$$

where $u_{1}, u_{2}, \ldots u_{m}$ are the utilities of the $m$ individuals in the economy. Aggregate social welfare is simply a summation of these (unweighted) utilities. A variation on this is the weighted utilitarian welfare function

$$
W=\sum_{i=1}^{m} \alpha_{i} u_{i}
$$

where the weight $\alpha_{i}$ reflects the 'importance' of individual $i$ to overall social welfare. This is most often employed to allow decision makers to effectively treat the marginal social welfare of income as being constant across all individuals in society. This means that a $\$ 1$ gain or loss for a poor person is treated as having exactly the same impact on

\footnotetext{
${ }^{2}$ In that people have some positive value on additional increments, within the range under consideration.

${ }^{3}$ It remains an open question as to whether VSL could reasonably be adapted and applied to high cost, low probability events. While it may be true that peoples' cognitive limitations may preclude eliciting a reliable WTP, more fundamentally it would require substantial theoretical advances and adaptations that are clearly beyond the bounds of this article.
} 
social welfare as the same gain or loss for a rich person (see for example, Jones-Lee, 1989 p.33).

In the context of a VSL the elicited WTP serves as a proxy for these utilities from the risk reduction, indicating for each individual her/his marginal rate of substitution of income for risk of death (i.e. the rate at which the individual will trade their money income for risk reduction), $m_{i}$. Under current practice, the arithmetic mean of WTP for the affected group is then taken as the VSL.

The empirical implication of this is perhaps slightly unpalatable. Effectively, it implies a higher VSL for richer members of society than for poorer members of the same society. The same point can be made in respect of age $\left(\mathrm{VSL}_{\text {young }}>\mathrm{VSL}_{\text {old }}\right)$ since WTP tends to decline with age.

However, we are hard pressed to identify any cases where governments apply this theoretically justifiable type of differentiation ${ }^{4}$. Instead, for any given context - such as road transport - common values are typically applied across the whole of society, regardless of the income level, age-band or any other personal or cultural characteristics of the specific group affected.

In spite of this tendency to apply a uniform VSL in any given context, so far as we are aware no satisfactory theoretical foundation has so far been provided that justifies the application of a common WTP-based VSL equal to, say, the overall population arithmetic mean of individual marginal rates of substitution (MRS) of wealth for risk of death by a given cause, other than under conditions which from a practical point of view appear somewhat implausible (see, for example, Bergstrom, 1982 or Dehez and Drèze, 1982).. Baker et al. (2008) explore in detail the kind of axiomatic foundation required to justify

\footnotetext{
${ }^{4}$ One notable exception is apparently Health Canada which, according to Alberini et al. (2002), applies a VSL equal to only $75 \%$ of its "standard" value to those aged 65 and over. In addition, in the UK at least some healthcare allocative decisions are based upon the so-called "Quality-Adjusted Life Year" (or "QALY") methodology, together with a WTP-based value of a life-year. Strictly applied i.e. using a constant QALY, this procedure will clearly also differentiate between patients on the basis of remaining life expectancy and hence age. However, Jones-Lee et al.(2007) show that with the use of a varying QALY (one that increases with age) this will not necessarily be the case.
} 
equal valuation with a view to establishing what would in fact constitute a plausible normative rationale for the uniform monetary valuation of safety for any given type of risk. This effectively relaxes the assumption of constant marginal utility of income and instead assumes constant marginal welfare of survival probability ${ }^{5}$.

In this paper, we present a practical and theoretically justifiable method based on this framework that social decision makers can use to calculate a common VSL that remains consistent with CBA but unaffected by the particular distributional and demographic characteristics of that society, if so desired.

\section{A Framework for a Common VSL}

Consider a society of $\mathrm{n}$ individuals, each with a survival probability for a forthcoming period. Then suppose that the objective is to maximize a weighted-additive utilitarian social welfare function of the form:

$$
\mathrm{V}=\sum_{\mathrm{i}=1}^{\mathrm{n}} \mathrm{a}_{\mathrm{i}} \mathrm{u}_{\mathrm{i}}\left(\mathrm{w}_{\mathrm{i}}, \mathrm{p}_{\mathrm{i}}\right)
$$

where $\mathrm{V}$ is an index of overall social welfare (or "value"); $\mathrm{u}_{\mathrm{i}}\left(\mathrm{w}_{\mathrm{i}}, \mathrm{p}_{\mathrm{i}}\right)$ is the $\mathrm{i}^{\mathrm{th}}$ individual's cardinal utility of wealth, $\mathrm{w}_{\mathrm{i}}$, and survival probability, $\mathrm{p}_{\mathrm{i}}$, for the forthcoming period and the $\mathrm{a}_{\mathrm{i}}$ are distributional weights ${ }^{6}$.

Underlying this social welfare function in conventional CBA are two important assumptions, namely that marginal social welfare of income is constant across individuals (i.e. $\$ 1$ buys the same amount of utility for a rich and a poor individual) and, further, that

\footnotetext{
${ }^{5}$ The interested reader is directed to Baker et al. (2008) for a detailed technical exposition of the outcome of this change in assumptions (i.e. a common VSL) and the axiomatic conditions that the underlying social welfare function must comply with.

${ }^{6}$ This is essentially the type of Benthamite utilitarian social welfare function proposed in Harsanyi (1955) and Broome (1991).
} 
the marginal social welfare of survival probability varies (i.e. a risk reduction generates different changes in utility for different individuals). In a break with these conventional CBA assumptions, Baker et al. (2007) show that if instead it is assumed that the marginal social welfare of survival probability is constant, this provides an axiomatic foundation for a common VSL. In conjunction with this assumption, we now show that for any public projects funded by lump sum taxes, it is possible to calculate a common VSL that can still be considered consistent with the tenets of CBA.

Consider a safety improvement financed by uniform per capita lump sum tax, $x$, levied on everyone in a society comprising $n$ individuals. In the following, $\delta$ defines a small (marginal) change so, for example, if $p_{i}$ is the probability of an event occurring for individual $I$, then $\delta \mathrm{p}_{i}$ denotes a small change in the probability of occurrence of that event for individual $i$.

Thus, we denote by $\delta \boldsymbol{p}_{i}$ the reduction in probability of death that is just large enough to ensure that paying tax $x$ and enjoying risk reduction $\delta \mathrm{p}_{i}$ leaves $\boldsymbol{i}^{\text {th }}$ individual no worse off then necessarily:

$$
\boldsymbol{m}_{i} \delta \boldsymbol{p}_{i}=\boldsymbol{x}, \quad \boldsymbol{i}=1,2----\boldsymbol{n} .
$$

where $m_{i}{ }^{t h}$ is the $i$ 'th individual's marginal rate of substitution (MRS) of wealth for risk of death i.e. the rate at which the individual $i$ is willing to trade off wealth against the risk of his or her premature death.

By rearranging algebraically, we can establish the size of the risk reduction that will just be sufficient to make it worth $\mathrm{x}$ to the individual, that is:

$$
\delta \boldsymbol{p}_{i}=\frac{\boldsymbol{x}}{\boldsymbol{m}_{i}}, \boldsymbol{i}=1,2----\boldsymbol{n}
$$

It then follows that the expected number of lives saved by the risk reduction is given by: 


$$
\sum_{n} \delta p_{i}=\sum_{n} \frac{x}{m_{i}}
$$

which is the same as:

$$
=x \sum_{n} \frac{1}{m_{i}}
$$

In addition, aggregate WTP for the risk reduction is equal to $n x$. It then follows that aggregate WTP per statistical fatality prevented (VSL) is given by:

$$
\mathrm{VSL}=\frac{n x}{x \sum_{n} \frac{1}{m_{i}}}
$$

and canceling $x$ from the numerator and denominator gives

$$
=\frac{n}{\sum_{n} \frac{1}{m_{i}}}
$$

which is, by definition, the harmonic mean ${ }^{7}, \hat{\boldsymbol{m}}$, of $\boldsymbol{m}_{\boldsymbol{i}}$

Notice also that if the social welfare function is structured so that marginal social welfare of survival probability is constant across all $i$, then, provided risk reductions continue to prevent one statistical fatality, these risk reduction can be re-distributed in any way and VSL remains unaffected i.e. remains equal to $\hat{\boldsymbol{m}}$.

\section{Conclusions}

Under standard (unweighted) social cost-benefit analysis the so-called "VSL" or value accorded to a safety improvement that will prevent one "statistical fatality" (i.e. that will

\footnotetext{
${ }^{7}$ In the context of VSL, the more commonly used arithmetic mean is simply the sum of individual $m_{i}$ 's divided by the number of individuals. The harmonic mean is simply a different kind of average. Thus, the harmonic mean of $m_{1}, m_{2}, \ldots m_{n}$ is $\hat{m}=\frac{n}{\frac{1}{m_{1}}+\frac{1}{m_{2}}+\ldots+\frac{1}{m_{n}}}=\frac{n}{\sum_{i=1}^{n} \frac{1}{m_{i}}}$ i.e. the reciprocal of the arithmetic
} mean of the reciprocal of individual $m_{i}$ 's. 
generate small individual risk reductions which reduce the mathematical expectation of the number of fatalities by one) is given by the arithmetic mean of individual marginal rates of substitution of wealth for the risk of death by the cause concerned, where this mean is taken over the group of people affected by the safety improvement. To the extent that these marginal rates of substitution will typically depend upon the income, age and other personal characteristics of those affected by the safety improvement, the logic underpinning standard cost-benefit analysis would seem to require that the VSL employed in the evaluation of a safety improvement that affects a poorer (or older) group in society should be smaller than the value applied to a wealthier (or younger) group.

But in those countries that do in fact use values of safety based on willingness-to-pay, no such differentiation actually occurs and instead a common VSL - independent of income, age, or other personal characteristics - is typically applied in the evaluation of safety projects in any particular context (such as road transport). Clearly, though, if a normative rationale is to be provided for this "uniform valuation of safety" approach then this will have to rely upon value judgments that differ somewhat from those underpinning conventional social cost-benefit analysis. This paper provides such a rationale and has demonstrated that, at least for small variations in wealth and the risk of death, a framework for a common VSL can be formulated and easily applied (by simply calculating the harmonic, rather than the arithmetic mean).

In closing, we note that VSL is a probabilistic approach to risk management and therefore incorporates randomness into the framework, in the sense that human behaviour can never be fully controlled and accidents will continue to happen to a priori anonymous members of society. Under this approach zero risk (a non-marginal change) is infeasible. This contrasts with the approach of Vision Zero (Johansson, 2008) which is essentially deterministic in nature and therefore holds out the possibility that because all human behaviour is in some way causal, it is possible to reduce risk to zero. Whilst on the face of it the two approaches may appear to be incompatible, on careful reflection, from a purely practical point of view we see no reason why the two tools cannot be used in conjunction with each other by risk managers. Indeed, we see the VSL framework as 
actually aiding in resource allocation if society adopts a Vision Zero approach. A VSL framework allows the risk manager to assess the benefits of the next iteration (i.e. safety project) compared to the costs. The result of this may help in determining the appropriate timeframe for implementation since it seems to us an unavoidable fact of economic life that one extra safety project means another, perhaps equally worthwhile, project elsewhere must be given up in a resource constrained world. While risk behaviour may or may not be ultimately deterministic in nature, it would become increasingly costly to deliver marginal safety improvements as a country progressed down the long road to Vision Zero. The question we (and a VSL framework) will continue to ask is - is it worth it?

\section{References}

Alberini, A., Cropper, M., Krupnick, A. and Simon, N.B. (2002) "Does the Value of Statistical Life Vary with Age and Health status? Evidence from the U.S.A. and Canada." Resources for the Future, Discussion Paper No. 02-19.

Arrow, K.J. (1951). Social Choice and Individual Values (2nd ed., 1963). New York,Wiley,

Baker, R., Chilton, S. Jones-Lee, M. and Metcalf, H. (2008). Valuing Lives Equally: Defensible Premise or Unwarranted Compromise? Journal of Risk and Uncertainty, $36(2), 125-138$.

Bergstrom, T.C. (1982) "When is a Man's Life Worth More Than his Human Capital?" in Jones-Lee, M. W. (editor) The Value of Life and Safety, Amsterdam, North Holland.

Broome, J. (1991) Weighting Goods, Oxford, Basil Blackwell 
Dehez, P and Drèze, J. H. (1982) "State Dependent Utility, the Demand for Insurance and the Value of Safety" in Jones-Lee, M. W. (editor) The Value of Life and Safety, Amsterdam, North Holland.

Harsanyi, J.C. (1955) "Cardinal Welfare, Individualistic Ethics and Interpersonal Comparisons of Utility”, Journal of Political Economy, 83,309-321.

Johansson, R. 2008 Vision Zero - Implementing a Policy for Traffic Safety. Safety Science (this issue).

Jones-Lee, M.W. (1989) The Economics of Safety and Physical Risk, Oxford, Basil Blackwell.

Jones-Lee, M., Loomes, G. and Spackman, M. (2007) Human Costs of a Nuclear Accident: Final Report. Health and Safety Executive, London.

Somanathan, E. (2006) "Valuing Lives Equally: Distributional Weights for Welfare Analysis", Economic Letters, 90, 122-125.

Viscusi, W. K. (1998) Rational Risk Policy. Oxford: Oxford University Press. 